\title{
ГАУДИ В ПСИХОЛОГИИ
}

\section{В.А. ПЕТРОВСКИЙ}

${ }^{a}$ Национальный исследовательский университет «Высшая школа экономики», 101000, Россия, Москва, ул. Мясницкая, д. 20

\section{Резюме}

Два открывателя новизны, два мыслителя, один в науке, другой в искусстве - Владимир Лефевр и Антонио Гауди - обнаруживают глубинное персональное сходство: нестандартность решений, многообразие компетенций, проницательность интуиции, эстетику мысли, смелость фантазии - все это «их общее». Архитектор новаторской рефлексивной теории, В.А. Лефевр перебросил мост между двумя реалиями - по ту и по сю сторону Я человека. Теоретики-предшественники имели дело с переходами «внешнее - внутреннее». Но именно Лефевр построил модель, которая не только описывает, но и прогнозирует характер переходов между поведением и сознанием. Автор статьи предлагает некоторые интерпретации, позволяющие осмыслить элементы математического аппарата, используемого Лефевром, извлекая их психологический смысл (подобно тому как в естественных науках открывается «физический смысл» математических символов). С этих позиций в статье интерпретируются: внутриличностные транзакции между берновскими Родителем, Взрослым и Ребенком в момент принятия решений; факты несоответствия модели «принятия риска» Дж. Аткинсона эмпирическим данным (и предлагается модель, устраняющая несоответствие); феномены активной неадаптивности («бескорыстный риск», постановка «надситуативных» задач в познании, парадокс Эдипа); «субъектные сборки» во внутреннем пространстве личности, позволяющие ее целям воплощаться в ожидаемые результаты; феномены внутренней коммуникации «Я - другое Я», генерируемые посредством рекурсии, и др.

Ключевые слова: «внешнее - внутренне», материальная импликация, «золотое сечение», внутренние транзакции, выбор риска, интенциональные выборы, психофеноменология.

Это посвящение В.А. Лефевру я пишу в Барселоне, городе А. Гауди. Я не первый раз тут, но «адаптация» к чуду не наступает. Потому что именно Гауди, фантастическая мощь которого прорастает вверх сквозь время все еще не законченным храмом Святого семейства, не дает ощущения завершенности на фоне величия.
Я пишу о Лефевре и ощущаю присутствие Гауди. Время от времени повторяю про себя три слова: «Гауди в психологии». В какой-то момент понимаю, что это название моей будущей статьи.

Изобретатель рефлексивной теории В.А. Лефевр строго математически показал, что субъект сам о себе 
не может сказать: «Я - святой». Есть такие черты личности, которые существуют за пределами индивидуального самосознания человека (я называю такие черты «метаиндивидуальными»). Человек не может сказать о себе: «Я - герой», «Я - душевный», «Я - гений». Только другие такое могут - о нем ${ }^{1}$. Тем более великому человеку (художнику, ученому, писателю) и в голову не придет сравнивать себя с другим, великим. Мог ли Л.С. Выготский сам сказать о себе: «Знаете ли, я - Моцарт в психологии!» Конечно, нет! Но британский философ Стивен Тулмин именно так писал о Выготском.

Разумеется, не мне судить о святости или героизме человека, изменившего мое представление о психологии. Но то, что Лефевр - выдающийся архитектор психологии субъектности, «архитектор от бога» (так говорят о Гауди), для меня очевидно.

Современная психология, как и вся предшествующая психология, начиная с XX в. и далее вниз, по ступенькам истории, традиционно расколота надвое: интроспективная психология (феноменологическая психология - в величии ее разновидностей) и поведенческая психология (бихевиоризм во всех его оттенках и переливах). Россиянин, возможно, добавит: «культурно-деятельностный подход» (обязанный своим появлением Л.С. Выготскому, А.Н. Леонтьеву и уж, конечно, их пожизненному и бессмертному оппоненту, С.Л. Рубинштейну); однако оставим на время это важное уточнение, мы вернемся к нему ниже и ограничимся исторически сложив- шейся парой «интроспекционизм бихевиоризм».

Владимир Лефевр предложил теорию (выделим это слово!), способную преодолеть эту дихотомию. Его модель «готовности к биполярному выбору» связывает воедино субъективные и объективные аспекты активности. Изящная формула, неожиданное место в которой отводится оператору материальной импликации « $\rightarrow »$, в два шага связывает мир внутренний, субъективный, существующий по сю сторону Я, и мир внешний, объективный, по ту сторону Я. В этой формуле всего четыре символа: $a_{1}$ - «давление среды», $a_{2}-$ «образ давления среды», $a_{3}$ - «интенции» и $A-$ «готовность к биполярному выбору»:

$A=\left(a_{3} \rightarrow a_{2}\right) \rightarrow a_{1}, a_{i}$ принимает значения 0 или 1.

Два из этих символов, $a_{3}$ и $a_{2}$ (интенции и образ давления среды), относятся к миру внутреннему, а два других, $a_{1}$ и $A$ (давление среды и итоговая готовность к выбору), - к миру внешнему. Смотрим на эту, казалось бы, очень простую формулу (далеко не все, но кое-что гениальное действительно просто) и видим, что в ней спрятана, а точнее, вполне наглядно выявлена связь между мирами по обе стороны Я, или, скажем так, идея отраженности внешних контактов индивидуума со средой во внутреннем пространстве его бытия: одно как бы свернуто в другом. Впрочем, эта пружинная свертка «умеет» разворачиваться вовне, порождая готовность к действию.

\footnotetext{
${ }^{1}$ Сочтем ли мы «душевным» того, кто сам о себе говорит: «Я - душевный»?!
} 
Мы видим, как элементы субъективного мира, $a_{3}$ (интенции) и $a_{2}$ (образ давления среды), вступая в контакт друг с другом (все та же несколько загадочная импликация « $\rightarrow)$, «обращены» вовне и в контакте с элементом объективного мира $a_{1}$ порождают объективную готовность к выбору того или иного полюса из возможных.

Нам, таким образом, открывается возможность перейти от общеметодологических размышлений, которые при всей их серьезности еще не образуют крепь теории (например, о «внешнем через внутреннее» или «внутреннем через внешнее» как принципах понимания психического, по Рубинштейну versus Леонтьев).

Символ $\longrightarrow »$ в составе рефлексивной теории - в некотором роде, повторяю, загадка! Ведь ничего общего с интуитивным «если... то...» (теперь такое понимание материальной импликации успешно усваивают пятиклассники в российских школах, и оно в общем соответствует общепризнанному). Въедливый читатель в недоумении: как Лефевру пришло в голову столь нестандартно обойтись с символом импликации, внедрив его в формулу, где никакое «если... то...» неуместно?! По-видимому, если отшучиваться, то ответ здесь был бы один: «В гениальную голову приходит и не такое!» ${ }^{2}$ И вот что замечательно: базовая импликативная модель выбора Лефевра, напоминающая о себе в разных построениях теоретика, прекрасно работает, предсказывая результаты эмпирических исследований и наблюдений (его собственных и сторонних). Постулат, кажущийся столь необычным, полностью себя оправдывает (чем не знак красоты и состоятельности теории?).

Гауди, как известно, порой «с места», интуитивно, руками, создавал то, что потом еще долго интриговало последователей корпеть над вопросами «что стоит за этим?» и «как такое возможно?». К счастью, эти вопросы мы имеем возможность сегодня напрямую обсуждать с творцом рефлексивной теории (Петровский, 2013б). В Барселоне, на фоне храма Гауди, к этим вопросам мы еще на минуту-другую вернемся.

Формула биполярного выбора и ее «непрерывная» модификация,

$A=a_{1}+\left(1-a_{1}\right)\left(1-a_{2}\right) a_{3}$, при $0 \leqslant a_{i} \leqslant 1$,

позволяют интерпретировать и прогнозировать нетривиальные феномены, обнаруживаемые в экспериментах. В слово «нетривиальное» я вкладываю особый смысл: насколько результаты исследования (факты, полученные эмпирически) отличаются от прогнозов независимых экспертов, осведомленных об условиях испытания.

Взять хотя бы такой нетривиальный факт, имеющий под собой нетривиальную объяснительно-прогностическую модель Лефевра (конечно, читатели, знакомые с его теорией, заранее знают ответ, поэтому вопрос, который я бы хотел задать экспертам, явно не к знатокам).

Испытуемый раскладывает на две кучки «правильные» и «неправильные» фасолинки; они на самом деле все «правильные» (практически одинаковые по форме), о чем испытуемый

\footnotetext{
${ }^{2}$ На молодежном сленге это звучало бы: «Слом башки».
} 
не знает. Как вы думаете, как распределятся фасолинки по кучкам, какой величины образуются горки «правильных» и «неправильных» зернышек? Возьму на себя смелость «от себя» резюмировать ответ тысяч «независимых экспертов»: кучки должны быть почти равны, $\approx 50 \%$ «правильных», $\approx 50 \%$ «неправильных» фасолинок. Теперь внимание правильный ответ: в одной кучке $\approx 62 \%$, в другой $\approx 38 \%$ (не так уж существенно, сколько в какой «правильных», сколько «неправильных», но чаще всего больше кучка «правильных» фасолинок). Модель готовности субъекта к биполярному выбору предсказывает такой результат!

Итак, нам открываются не только неожиданные (нетривиальные) результаты исследования, но и неожиданная возможность их математически предсказать. Добавим: соотношение $62 \% \div 38 \%$ - хорошо известное с античных времен «золотое сечение» - характеристика совершенно- го отношения между величинами, образующими целое: $0.62+0.38=$ $=0.62+0.62^{2}=1$. В.А. Лефевру удается не просто эмпирически «уловить» («заметить», «пронаблюдать») присутствие «золотого сечения», но и раскрыть логику его соучастия в процессах выбора. Таковы неочевидные следствия объединения в одной модели феноменологических и поведенческих аспектов активности.

Скромная на вид импликативная форма, связывающая субъективный и объективный миры, позволяет Лефевру создавать изящные, легкие, прочные логические конструкции. Ассоциация с Гауди напрашивается. Взять хотя бы ветвистые, уходящие ввысь, раскидистые деревья-опоры множественных исходов-выборов в «Космическом субъекте» (Лефевр, 1996) и в подкупольной «Алгебре совести» (Лефевр, 2004) (приведу без комментариев только три рисунка из многих лефевровских (рисунок 1).

На рисунках мы не находим стрелочки импликации « $\gg$. Она здесь

\section{Рисунки В.А. Лефевра}

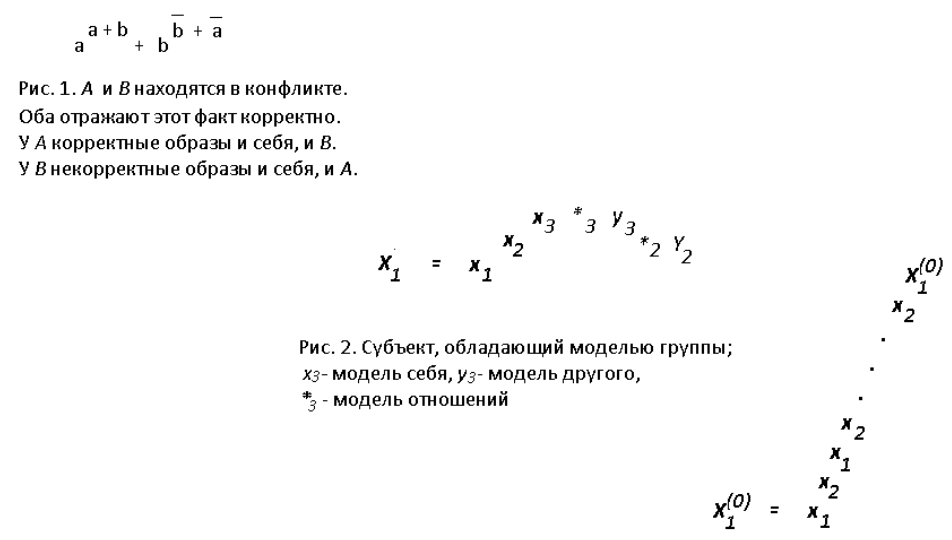


замещается степенью, в которую математически корректно возводятся переменные - «несущие» элементы конструкции (переход от импликативной к степенно́й форме также впечатляющая находка архитектора-теоретика!). Разгадать «стрелочку» импликации и основанные на них «степенну́ю» и непрерывную формы записи - подарок, великодушно предоставленный автором рефлексивной теории своим последователям.

Будем считать, что X - это запрос субъекта на приобретение дополнительных внешних ресурсов Y, компенсирующих дефицит потенциальных внутренних ресурсов субъекта, равный, соответственно, 1 - Х (здесь 1 символизирует весь потенциал внутренних ресурсов субъекта); в булевой записи - $7 \mathrm{X}$ («не-X»). Логично допустить, что внешний ресурс Y присваивается субъектом не полностью, не «целиком», но в меру заинтересованности субъекта в присвоении, чему соответствует произведение XY, или, в булевой записи, $\mathrm{X} \wedge \mathrm{Y}(\ll \mathrm{X}$ и $\mathrm{Y} \gg)$. Объединив потенциальный ресурс, нуждающийся в восполнении, и новоприобретенный ресурс, получаем то, что может быть названо состоятельностью субъекта (все то, что вслед за В.А. Лефевром может быть названо также статусом: этическим (Лефевр, 2004), логиче- ским (Петровский, 2013а), «возможностным» etc). Таким образом, имеем: $\mathrm{X} \rightarrow \mathrm{Y}=1-\mathrm{X}+\mathrm{XY}$, а в булевой форме, с использованием знака дизъюнкции «V» («или»), это: $7 \mathrm{X}$ V $\mathrm{X} \wedge \mathrm{Y}$ (потенциальный внутренний ресурс вместе с присвоенным внешним ресурсом). Стрелочка « $\rightarrow$ в этом случае интерпретируется как оператор восполнения дефицита внутреннего ресурса, реализуемого с опорой на внешний ресурс (отсюда и направленность стрелочки-запроса).

Опираясь на подобное понимание, можно видеть, как работают булева модель Лефевра и ее модификации с использованием аппарата решеток - модель «нормативного поведения» (Таран, 2000, 2001) в контексте психологии личности. В поле зрения исследователей-персонологов оказываются:

- внутренние транзакции личности; в транзактном анализе Э. Берна различные «части» личности (эгосостояния Родитель, Взрослый, Ребенок) могут придерживаться различных устремлений; интерпретируя их взаимоотношения в терминах булевой модели Лефевра и модели нормативного поведения, Т.А. Таран удается предсказать, при каком соотношении интересов личность совершит разумный выбор;

- «выбор риска» в модели Дж. Аткинсона (Atkinson, 1957, 1964;

${ }^{3}$ Думаю, мои коллеги - транзактные аналитики, преодолев предубеждение перед формулами, испытали бы некоторое удивление, узнав, что лефевровский логико-математичекий аппарат может быть эффективно использован для описания внутренних транзакций между эго-состояниями Взрослый, Родитель, Ребенок в динамике личности. Например, если Ребенок, т.е. детская часть личности, чего-то не хочет, от чего-то активно отказывается («не хочу!», «не буду!»), то Взрослый может добиться желаемого, используя рациональные аргументы («ты мог бы», «есть смысл попробовать»); однако такое возможно только тогда, когда Родитель уходит в сторону, не 
Хекхаузен, 2003) и мультисубъектной модели готовности личности (Петровский, 2013а) к выбору в развитие модели Лефевра (удается интерпретировать несоответствие модели Аткинсона эмпирическим данным и предложить интерпретацию, устраняющую несоответствие) (Петровский, 2006);

- феномены активной неадаптивности («бескорыстный риск», постановка «надситуативных» задач в познании, парадокс Эдипа ${ }^{4}$ ) (Петровский, 2013a);

- «субъектные сборки» во внутреннем пространстве личности, позволяющие ее целям воплощаться в ожидаемые результаты (что соответствует «интециональным выборам» В. Лефевра и при этом расходится с законом «гетерогении целей» В. Вундта) (Петровский, 2008a, 2013a);

- феномены внутренней коммуникации «Я - другое Я», генерируемые посредством рекурсии - многократного удвоения Я в роли опоры при разрешении проблемных ситуаций (на основе эксплораторного факторного анализа было эмпирически показано, что при этом актуализируется представление о себе в качестве «иного» Я, отличающегося от наличного Я предприимчивостью, креативностью, успешностью, - см.: Евченко, 2015);
- феномены «рефлексивной возгонки» и «рефлексивной редукции» влечений (Петровский, 2013а; Чернышкова, 2012).

Математические модели Лефевра охватывают всю сферу психического, заключая в себе двусторонние переходы субъективного и объективного друг в друга. Неслучайно автор рефлексивной теории называет свои разработки «исчисляемой психофеноменологией». Его теория - отнюдь не колеблется «на качелях между душой и телом» (так называется одна из интересных книг недавнего времени под редакцией В.П. Зинченко). Его теория связывает работу души и действия тела, соотнося «реальное», «знаемое», «осознанное».

Беру на себя смелость сказать, что часто мы смешиваем эти понятия либо разводим их чисто словесно. Но именно Лефевр показал, что такие «разводы», такое смешение недопустимы. И в рефлексивных играх, и в перцепции, и в принятии человеком этических решений налицо интригующее несовпадение внешнего и внутреннего, противоречивые отношения между реальным, знаемым, осознанным.

Вот еще один пример, непосредственно относящийся к сказанному: это поразительная находка Лефевра, описанная в «Алгебре совести».

оказывая давления («должен!»). Если же и Родитель объединится со Взрослым, «помогая» ему убедить Ребенка, то это - медвежья услуга: побеждает капризный Ребенок. Эти закономерности мы учитываем, ведя психотерапевтическую работу с клиентами, совместно «перенацеливая» их на новые решения.

4 «Парадокс Эдипа» известен в социологии как эффект влияния прогноза на прогнозируемые события. В психологии мы исследовали этот парадокс, предъявляя испытуемым предсказания, касающиеся их ответов на вопросы личностных опросников, что вело к заметному изменению ожидаемых, хорошо предсказуемых, ответов (использовались параллельные формы опросников). 
Автор постулирует (и эмпирически обосновывает) существование двух этических систем: для представителей первой из них компромисс между добром и злом есть зло, а для представителей второй этической такой компромисс системы - добро. «Для первой системы характерен запрет зла, например: “не лги”, для второй - призыв к добру: “будь правдив” (Лефевр, 2002). И вот тутто шокирующий «перевертыш» некая рефлексивная инверсия: первые проявляют тенденцию к компромиссу с людьми - они на деле терпимы и толерантны, стремятся разрешить конфликты; вторые склонны к борьбе до победы с конкретными людьми, к эскалации конфликта 5 .

Факты несовпадения и в то же время связи «субъективного» и объективного, «феноменологического» и «поведенческого», «сознания и деятельности», «рефлексивного» и «дорефлексивного», разных уровней «внутреннего» и «внешнего» - капитальное открытие психолога Лефевра. Подчеркиваю - психолога, так как Лефевр не только психолог (сам о себе он сказал мне доверительно: «Я - астроном»). В этих заметках я почти не затрагиваю другие ипостаси авторства уникального ученого-теоретика $^{6}$. Достаточно «одной» психологии, чтобы со временем оценить выдающийся вклад Лефевра в науку ${ }^{7}$.

Психология, согласно Б.М. Кедрову, занимает в системе наук центральное место, соприкасаясь с естественными и гуманитарными науками. Кедров писал о зависимости психологии от наук о природе, обществе и культуры, а Ж. Пиаже, приветствуя подход Кедрова, подчеркивал обратную зависимость, говоря о вкладе психологии в гуманитарное и естественно-научное знание. «Исчисляемая психофеноменология», занимая центральное место в «науке Лефевра», соприкасается вполне непосредственно с другими исчисляемыми феноменологиями; обозначим их соответственно:

- социальная феноменология («Конфликтующие структуры» - см.: Лефевр, 1973; более поздние работы, посвященные «рефлексивным играм», и - «ничуть не игровым» военным и политическим решениям ${ }^{8}$ ); - этическая феноменология («Алгебра совести»);

\footnotetext{
${ }^{5}$ Эти наблюдения и выводы из теории двух этических систем должны были бы вызвать смятение в головах тех исследователей, которые судят об общественных настроениях и настроях людей, исходя из их (респондентов) мнений о себе и окружающих, правда, далеко не всем социологам по сердцу расшифровывать странные, бегущие вверх формулы вдогонку за мыслями автора.

${ }^{6}$ Более полно о других аспектах рефлексивной теории речь идет в интервью «Космизм рефлексии Лефевра» (Петровский, 2013б).

${ }^{7}$ Насколько психологи, авторы учебников психологии, смогли оценить этот вклад - отразить его в своих учебниках? К сожалению, до сих пор разработки В.А. Лефевра не получили подобающего освещения в психологической литературе вообще и в учебной литературе по психологии в частности. Но это, конечно, особый вопрос, я думаю он будет решен со временем (может быть, к моменту завершения храма Святого семейства?).

${ }^{8}$ Недавно узнал: В.А. Лефевр в настоящее время работает с мозговым центром CADS по проблемам, связанным с «войной с терроризмом»; «руководство этой организации утверждает, что
} 
- герменевтическая феноменология (язык изображений для описания внутреннего мира человека, в том числе литературных персонажей);

- астрофизическая феноменология («Космический субъект», «Что значит одушевленность?»).

Замечательное открытие, сделанное В.А. Лефевром, описывает связь между силой внешнего (физического) стимула и интенсивностью его субъективного переживания. Отталкиваясь от формальной модели субъекта и интерпретируя осознание как «вид существования термодинамических характеристик нейронных сетей, проводящих вычислительные процессы», В.А. Лефевр предлагает термодинамическую модель субъекта, позволяющую вывести из нее психофизические законы Фехнера и Стивенса.

«Исчисленные» Лефевром понятия свободы, свободы воли, совести, веры, конфликта, субъектности, самой души - исключительное завоевание ученого, который на своем опыте показал, что не только в естествознании, как писал И. Кант, но и в гуманитарных науках, прежде всего в психологии, по-видимому, есть лишь столько настоящей науки, сколько в ней математики (это положение оспаривается сегодня многими, но, я думаю, чаще из страха и от бессилия перед ней, чем по иным соображениям). Все эти понятия служат преодолению пропасти между двумя пониманиями мира, двумя парадигмами - есте- ственно-научной и гуманитарной; в психологии это противостояние «объяснительной» и «описательной», «феноменологической» и «поведенческой» психологии, «психологии сознания» и «психологии поведения».

Продолжая тему, поднятую Л.С. Выготским в конце 1920-х гг. о кризисе методологических основ психологии, С.Л. Рубинштейн писал, что сущность этого кризиса состоит в поляризации психологии сознании и бихевиоризма (Рубинштейн, 2000).

Работы Лефевра намечают выход из этого кризиса.

...Нет, пожалуй, «намечают» - это не точно сказано! Они не столько «намечают» выход из кризиса, сколько выводят из него; в работах создателя рефлексивных моделей активности показано, чего можно достичь «по ту сторону» кризиса - и нового понимания, и новых фактов, и новых практик. Разработки В.А. Лефевра возвышают роль психологии как науки, способной сделать себя своим собственным предметом, обратить результаты психологических исследований, проведенных на испытуемых, в источник их собственных представлений о себе, встроить психологическое знание в движение жизни, увидеть в земном человеке черты космического субъекта.

Все построения Лефевра, конструктора новой «формулы человека» - методолога, философа, герменевтика, математика, астрофизика, психолога, - в конечном счете, устремлены вверх, за пределы земного.

смогло точно предсказать последовательность целого ряда палестинских терактов» (Википедия. Свободная энциклопедия [Электронный ресурс]. URL: https://ru.wikipedia.org/wiki/ Лефевр,_Владимир_Александрович; посл. измен. страницы: 02:29, 20.08.2016). 
Все построения Гауди, «конструктора XX в.» (Л. Корбузье) - строителя, скульптора, художника, архитектора, человека, сопровождавшего «все свои действия практикой христианских добродетелей», убежденного, «что без них нравственность поведения невозможна» (С. Мартинелл), - устремлены вверх, во Вселенское запределье.

Нестандартность решений, многообразие компетенций, проницательность интуиции, эстетика мысли, смелость фантазии - все это «их общее». И еще главное, сущностное: опыт воплощения идеи добра, сводя- щий вместе мысль, интуицию, знание, красоту, смелость (оба - первопроходцы).

...Гауди не поднял свой храм выше окружающих гор. Он полагал, что творение рук человеческих не может быть выше творенья Божьего - высшей точки горы. Но если вровень с природой, то можно.

Тех же принципов, мне думается, придерживается В.А. Лефевр.

Как истинный ученый, он скромен. Строит здание своей теории вровень с космосом, не выше.

\section{Литература}

Лефевр, В. А. (1973). Конфликтующие структуры (2-е изд., перераб. и доп.). М.: Советское радио.

Лефевр, В. А. (1996). Космический субъект. М.: Ин-кварто.

Лефевр, В. А. (2002). Стратегические решения и мораль. Рефлексивные процессы и управление, 2(1), 24-26.

Лефевр, В. А. (2004). Алгебра совести. М.: Когито-Центр.

Евченко, Н. А. (2015). Внутренняя коммуникация «Я - другое Я» в динамике субъектных проявлений личности (Автореферат кандидатской диссертации, Национальный исследовательский университет «Высшая школа экономики», Москва).

Петровский, В. А. (2006). Уровень трудности задачи: метаимпликативная модель мотивации выбора. Психологический журнал, 27(1), 6-23.

Петровский, В. А. (2008а). Индивидуальность, саморегуляция, гармония. Консультативная психология и психотерапия, 1, 60-90.

Петровский, В. А. (2008б). Состоятельность и рефлексия: модель четырех ресурсов. Психология. Журнал Высшей школы экономики, 5(1), 77-100.

Петровский, В. А. (2013а). «Я» в персонологической перспективе. М.: Издательский дом Высшей школы экономики.

Петровский, В. А. (2013б). Космизм рефлексии Лефевра. Беседа с В.А. Лефевром. Психология. Журнал Высшей школы экономики, 10(2), 27-23.

Рубинштейн, С. Л. (2000). Кризис методологических основ психологии. В кн. С. Л. Рубинштейн, Основы общей психологии. СПб.: Питер.

Таран, Т. А. (2000). Многозначные булевы модели рефлексивного выбора. В кн. В. Е. Лепский (ред.), Рефлексивное управление. Сборник статей (с. 122-132). М.: Институт психологии PAH. 
Таран, Т. А. (2001). Булевы модели рефлексивного управления в ситуации выбора. Автоматика и телемеханика, 10, 103-117.

Хекхаузен, Х. (2003). Мотивация и деятельность (2-е изд.). СПб./М.: Питер/Смысл.

Чернышкова, Е. Ю. (2012). Рефлексия как условие динамики фрустрационного реагирования (Автореферат кандидатской диссертации, Национальный исследовательский университет «Высшая школа экономики», Москва).

Atkinson, J. W. (1957). Motivational determinants of risk-taking behavior. Psychological Revierw, 64, $359-372$

Atkinson, J. W. (1964). An introduction to motivation. Princeton, NJ: Van Nostrand.

Петровский Вадим Артурович - ординарный профессор, профессор, кафедра психологии личности, факультет социальных наук, департамент психологии, Национальный исследовательский университет «Высшая школа экономики», член-корреспондент РАО, профессор, доктор психологических наук.

Контакты: petrowskiy@mail.ru

\title{
Gaudi in Psychology
}

\author{
V.A. Petrovsky ${ }^{a}$ \\ ${ }^{a}$ National Research University Higher School of Economics, 20 Myasnitskaya str., Moscow 101000 \\ Russian Federation
}

\begin{abstract}
There are two path-breakers, two thinkers, one in science and the other in art - Vladimir Lefevr and Antonio Gaudi - that have a deep personal kinship: out-of-the-box decisions, diverse competences, incisive intuitions, aesthetics of thought, bold imagination - they have all these "in common". An architect of a ground-breaking reflexive theory, V.A. Lefevr built a bridge between two realiae - on this and on the other side of a human self. The theoreticians-predecessors dealt with transitions "inner - outer". But it is Lefevr, who built a model, which not only describes, but also predicts the pattern of transitions between consciousness and behavior. The author of this article offers some interpretations that will allow comprehending the elements of mathematical analysis that Lefevr uses, deriving their psychological meaning (as "physical meaning" of mathematical symbols is revealed in natural sciences). From this standpoint the article interprets intrapersonal transactions between Berne's Parent, Adult and Child in the moments of decision-making; facts of disagreement of the J. Atkinson's model of "decision-making" with the empirical data (and offers the model that corrects non-conformances); phenomena of active inadaptability ("altruistic risk", statement of the "above-situational" tasks in cognition, Oedipus paradox); "subjective assemblage points" in the inner space of personality, which help realize its goals in the anticipated results; phenomena of inner communications "me - the other me", generated by means of recursion, etc.
\end{abstract}

Keywords: intrinsic - extrinsic, material implication, golden ratio, inner transactions, choice of risk, intentional choices, psychophenomenology. 


\section{References}

Lefebvre, V. A. (1973). Konfliktuyushchie struktury [Conflicting structures] (2nd ed.). Moscow: Sovetskoe radio.

Lefebvre, V. A. (1996). Kosmicheskii sub"ekt [The cosmic subject]. Moscow: In-kvarto.

Lefebvre, V. A. (2002). Strategicheskie resheniya i moral' [Strategic decisions and morality]. Refleksionye Protsessy i Upravlenie, 2(1), 24-26.

Lefebvre, V. A. (2004). Algebra sovesti [The algebra of conscience]. Moscow: Kogito-Tsentr.

Evchenko, N. A. (2015). Vnutrennyaya kommunikatsiya "Ya - drugoe Ya" $v$ dinamike sub»ektnykh proyavlenii lichnosti [Inner communication "Me - the other Me"] (Extended abstract of Ph.D. dissertation, National Research University "Higher School of Economics", Moscow).

Petrovsky, V. A. (2006). Task difficulty level: Metaimplicative model of motivation of choice. Psikhologicheskii Zhurnal, 27(1), 6-23. (in Russian)

Petrovskiy, V. A. (2008a). Individual'nost', samoregulyatsiya, garmoniya [Individuality, self-regulation, harmony]. Konsul'tationaya Psikhologiya i Psikhoterapiya, 1, 60-90.

Petrovskiy, V. A. (2008b). Opulence and reflection: Four resources model. Psychology. Journal of Higher School of Economics, 5(1), 77-100. (in Russian)

Petrovskiy, V. A. (2013a). "Ya" v personologicheskoi perspektive [Self in the personological perspective]. Moscow: HSE Publishing House.

Petrovsky, V. A. (2013b). The cosmism of Lefebvre's reflection. Interview with V.A. Lefebvre. Psychology. Journal of Higher School of Economics, 10(2), 7-23. (in Russian)

Rubinstein, S. L. (2000). Krizis metodologicheskikh osnov psikhologii [The crisis of methodological principles of psychology]. In S. L. Rubinstein, Osnovy obshchei psikhologii [The principles of general psychology]. Saint Petersburg: Piter.

Heckhausen, H. (2003). Motivatsiya i deyatel'nost' [Motivation and activity] (2nd ed.). Saint Petersburg/Moscow: Piter/Smysl. (Transl. of: Heckhausen, H. (1980). Motivation und Handeln. Lehrbuch der Motivationspsychologie. Berlin: Springer. (in German))

Taran, T. A. (2000). Mnogoznachnye bulevy modeli refleksionogo vybora [Multivalued Boolean models of reflexive choice]. In V. E. Lepskii (Ed.), Refleksiznoe upravlenie. Sbornik statei [Reflexive management. Collected papers] (pp. 122-132). Moscow: Institute of Psychology of Russian Academy of Sciences.

Taran, T. A. (2001). Boolean models of reflexive control under choice conditions. Avtomatika $i$ Telemekhanika, 10, 103-117. (in Russian)

Chernyshkova, E. Yu. (2012). Refleksiya kak uslovie dinamiki frustratsionnogo reagirovaniya [Reflection as a condition for dynamics of frustration response] (Extended abstract of Ph.D. dissertation, National Research University "Higher School of Economics", Moscow).

Atkinson, J. W. (1957). Motivational determinants of risk-taking behavior. Psychological Reviere, 64, $359-372$.

Atkinson, J. W. (1964). An introduction to motivation. Princeton, NJ: Van Nostrand.

Vadim A. Petrovskiy - professor, Faculty of Social Sciences, School of Psychology, National Research University Higher School of Economics, D. Sc.

E-mail: petrowskiy@mail.ru 